\title{
Evaluation of Parasite Density, Plasma Total Bile Acids, Alanine Transaminase, Lactate Dehydrogenase and CD4 in Plasmodium Infected Patients Treated with Morinda lucida (Oowo)
}

\author{
Mathew Folaranmi Olaniyan", Elizabeth Moyinoluwa Babatunde
}

Department of Medical Laboratory Science, Achievers University, Owo, Ondo state, Nigeria

\begin{abstract}
Morinda Lucida has been tested to have antimalarial and antidibetic effect among other health benefits. It is commonly used for the treatment of malaria infection in Oke-Ogun and its environs. Despite the health usefulness of this extract little has been reported about its biochemical alterations. This work was therefore designed to evaluate the parasite density, plasma total bile acids, Alanine transaminase, Lactate dehydrogenase and CD4 in Plasmodium infected patients treated with Morinda Lucida (Oowo). Sixty four (64) HIV, HBsAg and anti-HCV seronagative Plasmodium infected patients visiting traditional hoimes in Oke-Ogun the Nothern part of Oyo state Nigeria for traditional malaria cure aged 5 to 73 years classified into Female $(n=34)$ and Male $(n=30)$ were investigated. Hepatitis B surface antigen (HBsAg) and anti-HCV tests were carried out by Enzyme Linked Immunozorbent Assay (ELIZA). HIV screening and confirmation were carried out by immuno-chromatographic and Immunobloting (Western blot) assays respectively. Fasting Plasma Total Bile Acids (TBA), Lactate Dehydrogenase (LDH) and Alanine aminotransferase (ALT) were carried out biochemically by spectrophotometry while CD4 cell count was carried out by cytoflowmetry using Partec Cyflow machine and reagent. The tests were carried out in the control and test subjects before and after the treatment with the raw liquid extract of the leaf of Morinda Lucida. The result obtained showed a significantly higher mean values of falciparum parasite density and plasma ALT in the plasmodium infected test subjects than the values of the parameters obtained in plasmodium non-infected control subjects before and after treatment of the plasmodium infected subjects with the raw liquid extract of Morinda lucida with $\mathrm{p}<0.05$. There was also a higher significant difference in the value of plasma LDH in the plasmodium infected test subjects before the administration of the extract than the result obtained in the plasmodium non-infected control subjects with $p<0.05$. A significantly higher value of plasma LDH was obtained in the test subjects before the treatment compared to the value of this parameter obtained in the test subjects after treatment $(\mathrm{p}<0.05)$. There was also a significantly higher mean value of TBA in the test subjects compared with the control after treatment $(p<0.05)$. There was no significant alteration in the mean values of the CD4 cell count in the subjects before and after treatment and also in test compared with the control subjects. This recent work showed significant alterations in the mean values of the plasmodium parasite density, ALT, LDH, TBA in the test subjects studied due to plasmodium infection and the effectiveness of the raw liquid extract of the leaf of Morinda Lucida in the treatment of malaria. Estimation of plasmodium parasite density, plasma ALT, LDH, and TBA should be considered in the treatment of malaria using the raw liquid extract of the leaf of Morinda Lucida.
\end{abstract}

Keywords Morinda Lucida, ALT, LDH, TBA, CD4, Parasite density, Raw liquid extract, Traditional, Malaria

\section{Introduction}

The species of Plasmodium (P) that cause malaria in human which include: $P$. vivax. P. ovale, P. malariae and $P$. falciparum are transmitted by female anopheles mosquito when the mosquito is taking a blood meal from man. The

* Corresponding author:

olaniyanmat@yahoo.com (Mathew Folaranmi Olaniyan)

Published online at http://journal.sapub.org/ajb

Copyright (C) 2014 Scientific \& Academic Publishing. All Rights Reserved pre-erythrocytic schizogony takes place in the liver. The presentation of malaria may include headache, fever, shivering, joint pain, vomiting, hemolytic anemia, jaundice, hemoglobin in the urine, retinal damage, and convulsions [1].

Morinda Lucida known as "Oowo" in Yoruba vernacular dialect of the people of Oke-Ogun and its environs at the Northern part of Oyo state, Nigeria has been analyzed to possess anti-malaria and anti-diabetic properties. It has also been emphasized that morinda lucida is good for the treatment of hypertension, stomach pain, liver problems, 
pneumonia, sleeping sickness and yellow fever and diabetes [2] [3]. Phytochemical tests carried out on the leaves of Morinda lucida indicated the presence of saponins, anthraquinones, cardenolides, alkaloids, sterols and tannins. Morinda lucida showed inhibitory activity against Pseudomonas aeruginosa and Staphylococcus aureus with no activity against Salmonella typhi at a concentration of $10 \mathrm{mg} / \mathrm{ml}$ [3]. Morinda Lucida is most frequently used $(7.87 \%)$ in South Western Nigeria [2]. Treatment regimens of malaria generally included drinking, bathing and steam inhalation of the aqueous herbal preparations for $4-10$ days or until symptoms of malaria disappear [3].

Saponins component of Morinda Lucida have been used as adjuvants in vaccines [4] [5] [6]. Intravenous injection of saponins could cause haemolysis of red blood cells. Saponins are a class of chemical compounds found in particular abundance in various plant species. They have a characteristic of a soap-like foaming. Saponins have many health benefits which include beneficial effects on blood cholesterol levels, cancer, bone health and stimulation of the immune system. Saponins have antitumor and anti-mutagenic activities and can lower the risk of human cancers, by preventing cancer cells from growing and could boost immunity. Plants produce saponins to fight infections by parasites. When ingested by humans, saponins also seem to help our immune system and to protect against viruses and bacteria. Saponins reduce bone loss and could act as antioxidant [4] [5] [6].

Alkaloids another major constituents of Morinda Lucida include: caffeine. theobromine and theophylline. Caffeine acts on the nervous system by blocking adenosine receptor thereby slowing down nerve cell acitivity. Caffeine stimulates the central nervous system, respiration and blood circulation. Caffeine also acts as a diuretic. Caffeine increases the circulation and oxidation of fatty acids. This is why caffeine is used by sportsmen to increase fatty acid metabolism. Caffeine is often used in combination with aspirin to treat headaches. Caffeine can also have negative impact on health, especially if overdosed [4] [5] [6].

Theobromine a constituent of Morinda Lucida has a similar effect than caffeine, but about 10 times weaker. Theobromine has diuretic, stimulant and relaxing effects. Theobromine can lower the blood pressure because it can to dilate blood vessels. Theobromine has stimulant properties, similar to caffeine. Unlike caffeine theobromine does not affect the central nervous system. Theobromine can also relax bronchi muscles in the lungs. Theobromine can be used as cough medicine. Studies indicate that theobromine acts on the vagus nerve, which runs from the lungs to the brain. Other actions of theophylline are: lowering of blood pressure, anti-inflammatory effect and chronotropic effect [5] [6].

Anthraquinone a phytochemical of Morinda Lucida include many important drugs (collectively called anthracenediones) and could be used as laxatives such as dantron, emodin, and aloe emodin, and some of the senna glycosides; antimalarials such as rufigallol; antineoplastics used in the treatment of cancer, such as mitoxantrone, pixantrone, and the anthracyclines; DNA dyes / nuclear counterstains for flow cytometry and fluorescence microscopy. Cardenolide glycosides are often toxic; specifically, they are heart-arresting. organic compounds with a characteristic ring structure many of which are found in plants (as some milkweeds), have an effect on the vertebrate heart like that of digitalis, and cause vomiting. Most alkaloids have a bitter taste or are poisonous when ingested [3].

Lactate dehydrogenase (LDH) catalyzes the interconversi on of lactic acid and pyruvic acid. The enzyme is composed of 4 peptide chains and exists in 5 isomeric forms. LDH is widely distributed throughout the body; highest concentrations are found in the liver, heart and skeletal muscle.LDH is a general marker of tissue damage and is often used to determine the root cause and location of damage. LD activity is significantly elevated during myocardial infarction. Maximum levels are reached 24 to 48 hours after the on set of chest pain and may remain elevated for 7 to 12 days postinfarction.Increased activity is also associated with stroke, kidney disease, liver disease, progressive muscular dystrophy, cancer, intestinal and pulmonary infarction [7].

Bile acids are synthesised in the liver as a breakdown product of cholesterol and secreted into the gall bladder. They are released into the small intestine where they solubilise dietary lipids such as cholesterol, aiding their absorption. Bile acids are reabsorbed from the portal blood by hepatocyte extraction and re-excreted into bile, passing through the enterohepatic circulation several times before final excretion [8]. The measurement of Total bile acids (TBA) in serum is a sensitive indicator of liver function. Fasting serum bile acids can be used in the diagnosis and prognosis of liver disease. Levels rise in many liver diseases, for example hepatitis and liver sclerosis. Abnormal levels in fasting patients or immediately after a meal can be used to detect liver disease and damage, impaired liver function, intestinal dysfunction and perhaps a gall bladder blockage[9] [10]. Bile acid measurement may detect some forms of liver disease earlier than standard liver tests because bile acids levels correspond to liver function, rather than liver damage. In veterinary medicine, bile acid measurement is considered to be a superior indicator of liver disease. Bile Acids provides a highly specific marker for use in the diagnosis and monitoring of various liver conditions supplying information that conventional markers like AST and ALT cannot. It is also one of the most sensitive markers for the early detection of liver dysfunction. Abnormal levels of Bile Acids are associated with obstetric cholestasis in pregnant women, hepatitis, liver sclerosis and liver cancer [11].

Aspartate aminotransferase (AST) or Alanine Aminotran sferase (ALT) is or are tested to give an indication of the degree of inflammation. They are present in hepatocytes and leak into the bloodstream if liver cells are damaged or injured [12]. Perhaps ALT is the most specific marker as AST can also be elevated in other disease states. The aminotransferases are a group of enzymes that catalyze the 
inter-conversion of amino acids and a oxoacids by transferring amino groups. The enzyme ALT (alanine aminotransferase or glutamate pyruvate transaminase) has been found to be in highest concentrations in the liver, with decreasing concentrations found in the kidneys, heart, skeletal muscle, pancreas, spleen and lung tissue respectively [12]. ALT measurements are used in the diagnosis and treatment of certain liver diseases (e.g. viral hepatitis and cirrhosis) and heart diseases. Extremely elevated levels of ALT can indicate acute hepatitis with moderately high levels indicating chronic hepatitis. Elevated levels of the transaminases can also be indicative of myocardial infarction, hepatic disease, muscular dystrophy and organ damage. Elevated levels of ALT in serum is rare except in parenchymal liver disease, since ALT is a more liver specific enzyme.ALT is often tested in combination with AST as part of a liver panel with ALT levels being higher in most types of liver disease [12].

$\mathrm{CD} 4+\mathrm{T}$ helper cells are white blood cells that are an essential part of the human immune system. They are often referred to as CD4 cells, T-helper cells or T4 cells. They are called helper cells because one of their main roles is to send signals to other types of immune cells, including CD8 killer cells. CD4 cells send the signal and CD8 cells destroy the infectious particle. If CD4 cells become depleted, for example in untreated HIV infection, or following immune suppression prior to a transplant, the body is left vulnerable to a wide range of infections that it would otherwise have been able to fight [13] [14].

Total bile acids, Alanine transaminase, and Lactate dehydrogenase are liver markers that increase in plasma concentration in liver injury/diseases. The pathophysiology of Plasmodium infection involves liver which could cause a significant alteration in the plasma level of liver markers [1]. It has been said that most of the medicinal plants used for traditional treatment are hepatotoxic due to either the phytochemical constituents or dosage [1] [2] [3].This recent work was therefore designed to evaluate the parasite density, plasma total bile acids, Alanine transaminase, Lactate dehydrogenase and CD4 in Plasmodium infected patients treated with Morinda Lucida (Oowo).

\section{Materials and Methods}

\subsection{Materials}

\section{Study area}

The study was carried out in ATISBO, Saki-East and Saki-West Local government areas of Oke-Ogun - the Northern part of Oyo state-Nigeria. The three local governments constitute the former Ifedapo Local government area of Oyo state and presently a Nigeria Federal Constituency. The three local governments share border with Kwara state-Nigeria, Ogun state-Nigeria and the Republic of Benin.

\section{Study design}

Experimental research design.

\section{Study population}

a. Sixty four (64) Plasmodium infected HIV, HBsAg and anti-HCV seronagative patients aged $5-73$ years that have not been treated with any malaria medication but have decided to be treated traditionally using Morinda Lucida leaf extract were recruited from fifteen (15) traditional homes in ATISBO, Saki-East and Saki-West Local government areas of Oke-Ogun - the Northern part of Oyo state-Nigeria. None of the subject was jaundiced as at the time of sample collection.

\section{Sample size}

Sixty four 64(84.2\%) out of the seventy six (76) Plasmodium infected patients (Female: $n=34$; Male: $n=30$ ) that visited the traditional healers between September, 2013 and April, 2014 for treatment that volunteered themselves for this study were recruited based on the inclusion and the exclusion criteria.

\section{Case selection procedure/s}

\section{Inclusion criteria}

Anicteric Plasmodium infected HIV, HBsAg and anti-HCV seronagative patients aged 5-73 years that have not been treated with any antimalarial medication but have volunteered to be treated with raw liquid extract of the leaf of Morinda Lucida in the traditional homes were recruited.

\section{Exclusion criteria}

1. Plasmodium infected patients that have been treated or being treated with antimalarial drugs were not recruited for the study.

2. Icteric Plasmodium infected HIV, HBsAg and anti-HCV seronagative patients aged $5-73$ years that have not been treated with any antimalarial medication were not included for the study.

3. Anicteric Plasmodium infected HIV, HBsAg and anti-HCV seropositive patients aged $5-73$ years that have not been treated with any antimalarial medication were not included in the study.

4. Anicteric Plasmodium infected HIV, HBsAg and anti-HCV seronagative patients aged $5-73$ years that have not been treated with any antimalarial medication were not included in the study but on drugs such as paracetamol, contraceptives, alcohol and have been taking cigarette were not included in the study.

\section{Blood Sample}

Five (5) milliliter of blood was collected into lithium heparinized bottle from each of the control and the test subjects before and after the administration of the raw liquid of extract Morinda Lucida (Oowo) after an overnight fasting for the estimation of Plasmodium parasite density, CD4 cell count, HIV, HBsAg and anti-HCV tests, plasma Alanine transaminase, Lactate Dehydrogenase Total Bile Acids, LDL 
and Total Cholesterol. The post treatment blood sample was collected after one week of administration.

\section{Preparation of the raw Liquid extract of Morinda Lucida (Oowo)}

The leaves of the Morinda Lucida were plucked and washed in water. The water was drained and the leaves were crushed or squished for the extraction of the liquid content into a container. A plastic cup with a capacity of $70 \mathrm{ml}$ was dedicated by the healers for the measurement of the extract to be administered into the patients. The liquid extract is freshly prepared on daily bases prior to administration. The raw liquid content of the leaf is extracted without the addition of water and also administered undiluted.

\subsection{Methods}

a. Based on the information obtained from the fifteen traditional homes visited in the three local governments about $70 \mathrm{ml}$ of the raw undiluted liquid extract of the Morinda Lucida leaf is administered to the patients on daily bases for at least one week.

b. Estimation of plasma Alanine Transaminase was carried out by Cobas C111 Auto-Chemistry Analyzer using the Reagent Kit of Roche Diagonostics, GmbhSandhoferstrasse, 116, D-68305, Mannheim. www.roche.com.

c. Estimation of Total Bile Acids was carried out on the plasma samples of the subjects using Randox reagent kit. The manufacturer's instruction was strictly followed.

Principle: Two reactions are combined in this kinetic enzyme cycling method. In the first reaction bile acids are oxidised by 3- $\alpha$ hydroxysteroid dehydrogenase with the subsequent reduction of Thio-NAD to Thio-NADH. In the second reaction the oxidised bile acids are reduced by the same enzyme with the subsequent oxidation of NADH to NAD. The rate of formation of Thio-NADH is determined by measuring the specific absorbance change at $405 \mathrm{~nm}$.

(Abreviations: NADH, NAD, Thio-NADH, Thio-NAD)

d. Screening for HIV Antibodies HIV screening were carried out using Immuno chromatographic kit (Chembio HIV 1 and 2 STAT-PAK). Positive samples were further confirmed by Western blot/Immunoblotting using Immunoetics Qualicode TM HIV 1 and 2 kit.

e. Screening for HbsAg by Enzyme-Linked Immunosorbent Assay (ELISA) The ELISA kit from BIORAD Monolisa HBsAg ULTRA EIA92430 Marnes-La-Coqutte-France was used. ELISA was done according to the manufactures instruction. The Optical density OD was read at $450 / 620$ to 700 nanometre. The cut off value was determined by the mean of negative control $+0.05(0.08)$. The test is valid if all values of negative control are lower or equal to 0.08 and Positive control was over 0.08 or equal to 1.0. A test sample is considered negative if the ratio value of sample: cut off value is lower than 1.0 and positive if equal to or greater than 1.0.

f. Screening for HCV Antibody by ELISA ELISA kit from DIA PRO Diagnostic Bioprobes 20099 Sesto San Giovanni (Milano)-Italy was used. ELISA was done according to the manufactures instruction The Optical density OD is read at 450/620 to 700 nanometre. The cut -off value is calculated as follows: $\mathrm{NC}$ (negative control) $+350=$ cut-off $(\mathrm{C})$, Calibrator mean value $=0.540, \mathrm{~S} / \mathrm{C}=1.4$ (where $\mathrm{S}=$ sample and $\mathrm{C}$ - cut off). $\mathrm{S} / \mathrm{C}=$ higher than 1.1. Any sample with a ratio value of sample /cut off less than 0.9 was considered negative and if higher than 1.1 is positive.

g. CD4 Count was Carried out by Cytoflometry Using the Reagent Kit of Partec and Partec CD4 Machine

h. Identification and the estimation of the density of Plasmodium parasite in the subjects were carried out as follows: Plasmodium spp was determined in the blood of the control and the test subjects using Giemsha thick blood staining technique described by Cheesbrough (,2002). Estimation of parasite number was carried out by multiplying average number of parasites per high power field (100x objective) by 500 within 10 fields [15] [16].

i. Plasma Lactate Dehydrogenase was estimated in the subjects using reagent kit of Randox. The manufacturer's instruction was followed strictly.

\section{Principle}

The LDH method measures the oxidation of L-lactate to pyruvate with simultaneous reduction of nicotinamide adenine dinucleotide (NAD). The change in absorbance at $340 \mathrm{~nm}$ due to the appearance of reduced NAD (NADH) is directly proportional to the LDH activity, since other reactants are present in non-rate limiting quantities and is measured using a bichromatic $(340,383 \mathrm{~nm})$ rate technique.

\section{Ethical Consideration}

The proposal was reviewed and approved by the Research and Ethical Committee of Baptist Medical Centre, Saki-Oyo state-Nigeria before the commencement of the work. This is to protect the interest of patients to ensure that the patients and the community are not harmed in any form by the procedure. Only plasmodium infected patients that volunteered themselves for the study were recruited.

\section{Statistical Analysis}

the values of the biochemical parameters obtained in the patients before and after treatment with the raw liquid extract were subjected to statistical analysis to determine the mean values, standard deviation and students' ' $t$ ' test, for $t$ value, $p$ value and level of significant at $0.01(99 \%)$ using online Student T-Test Calculator for 2 Independent Means on line at. http://www.socscistatistics.com/tests/studentttest 


\section{Result}

Table 1. The value of the Falciparum parasite density, Plasma LDH, ALT, TBA, and CD4 cell count

\begin{tabular}{|l|c|c|c|c|c|}
\hline & $\begin{array}{c}\text { Plasmodium } \\
\text { parasite } \\
\text { density/ } \boldsymbol{\mu L}\end{array}$ & $\begin{array}{c}\text { Plasma } \\
\mathbf{L D H}(\mathbf{U} / \mathbf{L})\end{array}$ & $\begin{array}{c}\text { Plasma ALT } \\
(\mathbf{U} / \mathbf{L})\end{array}$ & $\begin{array}{c}\text { Plasma TBA } \\
(\boldsymbol{\mu} \mathrm{mol} / \mathbf{L})\end{array}$ & $\begin{array}{c}\text { CD4 } \\
(\mathbf{c e l l s} / \boldsymbol{\mu L})\end{array}$ \\
\hline $\begin{array}{l}\text { Mean and Standard deviation of } \\
\text { the parameters in Normal } \\
\text { Control subjects n= 64 }\end{array}$ & 0 & $170 \pm 10.0$ & $25 \pm 2.0$ & $6.0 \pm 1.5$ & $700 \pm 20.5$ \\
\hline $\begin{array}{l}\text { Mean and Standard deviation of } \\
\text { the parameters in the test } \\
\text { subjects before treatment } \mathbf{n}=\mathbf{6 4}\end{array}$ & $895 \pm 30.1$ & $301 \pm 10.1$ & $46 \pm 3.0$ & $14 \pm 2.0$ & $645 \pm 25.2$ \\
\hline $\begin{array}{l}\text { Mean and Standard deviation of } \\
\text { the parameters in the test } \\
\text { subjects after treatment } \mathbf{n}=\mathbf{6 4}\end{array}$ & $65 \pm 16.1$ & $215 \pm 10$ & $49 \pm 2.5$ & $16 \pm 1.2$ & $676 \pm 27.3$ \\
\hline
\end{tabular}

Table 2. Comparative analysis of the values of the Falciparum parasite density, Plasma LDH, ALT, TBA, and CD4 cell count in the subjects

\begin{tabular}{|c|c|c|c|c|c|c|}
\hline & & $\begin{array}{c}\text { Falciparum } \\
\text { parasite } \\
\text { density / } \mu \mathrm{L}\end{array}$ & $\begin{array}{c}\text { Plasma } \\
\text { LDH (U/L) }\end{array}$ & $\begin{array}{c}\text { Plasma } \\
\operatorname{ALT}(U / L)\end{array}$ & $\begin{array}{c}\text { Plasma } \\
\text { TBA } \\
(\mu \mathrm{mol} / \mathrm{L})\end{array}$ & $\begin{array}{c}\text { CD4 } \\
\text { (cells } / \mu \mathrm{L})\end{array}$ \\
\hline \multirow{3}{*}{$\begin{array}{l}\text { Values obtained in } \\
\text { Control/values in test } \\
\text { subjects before } \\
\text { treatment }\end{array}$} & 't' value & 29.833333 . & 10.99651. & $5.824352 .$. & 3.2 . & 1.874085 \\
\hline & 'p' value & 0.000561 & 0.008169 & 0.028236 & 0.085341 & 0.201772 \\
\hline & comment & $\mathrm{P}<0.05^{\mathrm{s}}$ & $\mathrm{P}<0.05^{\mathrm{s}}$ & $\mathrm{P}<0.05^{\mathrm{s}}$ & $\mathrm{P}>0.05^{\mathrm{ns}}$ & $\mathrm{P}>0.05^{\mathrm{ns}}$ \\
\hline \multirow{3}{*}{$\begin{array}{l}\text { Values obtained in } \\
\text { Control/values in test } \\
\text { subjects after treatment }\end{array}$} & 't' value & 4.333333 . & 3.181981 . & 7.652514 & 5.547002 & 0.762138 . \\
\hline & 'p' value & 0.024673 . & 0.043094 & 0.008325 & 0.015498 & 0.262796 \\
\hline & comment & $\mathrm{P}<0.05^{\mathrm{s}}$ & $\mathrm{P}<0.05^{\mathrm{s}}$ & $\mathrm{P}<0.05^{\mathrm{s}}$ & $\mathrm{P}<0.05^{\mathrm{s}}$ & $\mathrm{P}>0.05^{\mathrm{ns}}$ \\
\hline \multirow{3}{*}{$\begin{array}{l}\text { Values obtained in test } \\
\text { subjects before } \\
\text { treatment/values in test } \\
\text { subjects after treatment }\end{array}$} & 't' value & 24.745819 . & 6.081118 & 0.707107 & 0.894427 & 0.970352 . \\
\hline & 'p' value & 0.000815 . & 0.012996 . & 0.276393 & 0.232739 & 0.217116 \\
\hline & comment & $\mathrm{P}<0.05^{\mathrm{s}}$ & $\mathrm{P}<0.05^{\mathrm{s}}$ & $\mathrm{P}>0.05^{\mathrm{ns}}$ & $\mathrm{P}>0.05^{\mathrm{ns}}$ & $\mathrm{P}>0.05^{\mathrm{ns}}$ \\
\hline
\end{tabular}

Note- ns: not significant

s: significant

The result obtained in this study is as shown in tables $1 \& 2$ above. The result showed a significantly higher mean values of Plasmodium parasite density and plasma ALT in the plasmodium infected test subjects than the values of the parameters obtained in plasmodium non-infected control subjects before and after treatment of the plasmodium infected subjects with the raw liquid extract of Morinda lucida with $\mathrm{p}<0.05$. There was also a higher significant difference in the value of plasma LDH in the plasmodium infected test subjects before the administration of the extract than the plasmodium non-infected control subjects with $p<0.05$. A significantly higher value of plasma LDH was obtained in the test subjects before the treatment compared to the value of this parameter obtained in the test subjects after treatment $(p<0.05)$. There was no significant difference in the mean values of the $\mathrm{CD} 4$ cell count in the subjects before and after treatment and also in test compared with the control subjects $(\mathrm{p}>0.05)$. There was also a significantly higher mean value of TBA in the test subjects compared with the control after treatment $(p<0.05)$. Also, no significant difference was obtained in the mean value of plasma LDH in the test and control subjects and also in the plasma value of ALT and LDH in the test subjects before and after treatment with the liquid extract $(\mathrm{p}>0.05)$.

\section{Discussion, Conclusions and Recommendations}

This work has been used to determine the alterations in the level of plasmodium parasite density, CD4 cell, LDH, ALT and TBA in the blood of Plasmodium infected patients treated with the raw liquid extract of Morinda lucida.

A significantly higher mean values of plasmodium parasite density and plasma ALT obtained in the plasmodium infected test subjects than the values of the parameters in plasmodium non-infected control subjects before and after treatment of the plasmodium infected subjects with the raw liquid extract of Morinda lucida. The mean values of the parasite density obtained before the treatment indicates plasmodium parasitaemia. The density however decreases after treatment as a result of the antimalarial effect of raw liquid extract of Morinda lucida [2] [3]. Raised plasma ALT in plasmodium infected ppatients could be as a result of the liver involvement in the pathophysiology of malaria convulsions [1]. Alanine Aminotransferase (ALT) is tested to give an indication of the degree of inflammation. They are present in hepatocytes and leak into the bloodstream if liver cells are damaged or injured [12]. 
Significantly raised plasma LDH level in plasmodium infected subjects than the control subjects and also in the test subjects before treatment than the value obtained in the test subjects after treatment with the raw liquid extract of Morinda lucida. These findings could be attributed to the fact that LDH is widely distributed throughout the body; highest concentrations are found in the liver, heart and skeletal muscle. LDH is a general marker of tissue damage and is often used to determine the root cause and location of damage. Plasmodium infection is also associated with haemolysis/tissue destruction. The liver is also involved at the pre-erythrocytic stage of the life cycle of Plasmodium which may affect its normal metabolic activities may also account for these findings. Decrease in plasma LDH after treatment could also be associated with the effectiveness of Morinda lucida extract as an antimalarial leading to the reduction in plasmodium parasite density that may bring about less tissue destructions [7].

There was also a significantly higher mean value of TBA in the test subjects compared with the control after treatment. This could be explained by the fact that there could be liver dysfunction / hepatopathy in malaria which may not be conveniently associated with the hepatotocxic effect of raw liquid extract of Morinda lucida. This is because there was no significant difference in the result obtained in the plasmodium infected patients when the plasma ALT and TBA levels before the administration of the extract were compared with the result obtained in the patients after treatment which may rule out hepatotoxicity as this also agrees with the findings of Oduola et al., [18] that evaluated hepatotoxicity and nephrotoxicity in Wistar albino rats exposed to Morinda lucida leaf extract and found that ingestion of Morinda lucida leaf extract has no toxic effect on liver and kidney functions.

The findings of this study could also be generally be attributed to the reports of Uzuegbu and Emeka [19] and Bhalla et al., [20] that there is evidence of liver dysfunction among the malaria infected patients.

\subsection{Conclusions}

This work has been used to evaluate parasite density, plasma total bile acids, Alanine transaminase, Lactate dehydrogenase and CD4 in Plasmodium infected patients treated with Morinda Lucida (Oowo). The findings of the study showed a significant alteration in the plasmodium parasite density, ALT, LDH and TBA in the test subjects due to plasmodium infection and the effectiveness of the raw liquid extract of the leaf of Morinda Lucida in the treatment of plasmodium infection.

\subsection{Recommendations}

Estimation of Plasmodium parasite density, Plasma TBA, ALT and LDH should be considered in routine monitoring of the treatment of malaria using the leaf of Morinda Lucida.

\section{REFERENCES}

[1] Brian M. Greenwood, David A. Fidock, Dennis E. Kyle, Stefan H.I. Kappe, Pedro L. Alonso, Frank H. Collins, Patrick E. Duffy. Malaria: progress, perils, and prospects for eradication. J. Clin. Invest. 2008; 118: 1266-1276. doi: 10. 1172/JCI33996 Full Text athttp://www.jci.org/articles/view/ 33996/files/pdf.

[2] Idowu O. A, Soniran O. T, Ajana. O. and Aworinde D. O. Ethnobotanical survey of antimalarial plants used in Ogun State,. African Journal of Pharmacy and Pharmacology, 2010; Vol. 4(2) pp. 055-060, Available online http://www.academi cjournals.org/ajpp ISSN 1996-0816.

[3] Bright Selorm Addy, Harry Tetteh Owodo, Reginald Nana Kofi Gyapong, Cynthia Onyinye Umeji, David Ntinagyei Mintah. Phytochemical Screening and Antimicrobial Study on the Leaves of Morinda lucida (Rubiaceae) Journal of Natural Sciences Research, 2013; Vol.3, No.14, http://www. iiste.org ISSN 2224-3186 (Paper) ISSN 2225-0921 (Online).

[4] Kutalek R and A prinz. African Medicinal Plants in Yaniv Z and U. Bachrach (eds) Handbook of medicinal plants: 2007: New Delhi, CBS Publishers.

[5] Oyedeji L. Drugless Healing Secrets: 2007; Ibadan, Panse Press.

[6] Odugbemi T. A Textbook of Medicinal Plants from Nigeria: 2008: Lagos, University of Lagos Press.

[7] Azuma M, Shi M, Danenberg KD, Gardner H, Barrett C, Jacques CJ et al. "Serum lactate dehydrogenase levels and glycolysis significantly correlate with tumor VEGFA and VEGFR expression in metastatic CRC patients.". Pharmacogenomics. 2007:8 (12): 1705-13. doi:10.2217/146 22416.8.12.1705. PMID 18086000.

[8] Russell DW. "The enzymes, regulation, and genetics of bile acid synthesis". Annu. Rev. Biochem. 2003;.72:13774. doi:10.1146/annurev.biochem.72.121801.161712. PMID 12543708 .

[9] Shima T1, Tada H, Morimoto M, Nakagawa Y, Obata H, Sasaki T, Park H, Nakajo S, Nakashima T, Okanoue T, Kashima K.Serum total bile acid level as a sensitive indicator of hepatic histological improvement in chronic hepatitis $\mathrm{C}$ patients responding to interferon treatment. J Gastroenterol Hepatol. 2000 Mar; 15(3):294-9.

[10] Chiang JY. "Bile acids: regulation of synthesis". J. Lipid Res. 2009:50 (10): 1955-66. doi:10.1194/jlr.R900010-JLR200. PMC 2739756. PMID 19346330.

[11] Hofmann AF. "The continuing importance of bile acids in liver and intestinal disease". Arch. Intern. Med. 1999: 159 (22): 2647-58. doi:10.1001/archinte.159.22.2647. PMID 10597755.

[12] Ghouri, N; Preiss, David; Sattar, Naveed. "Liver enzymes, nonalcoholic fatty liver disease, and incident cardiovascular disease: a narrative review and clinical perspective of prospective data". Hepatology. 2010: 52 (3): 1156-61. doi:10.1002/hep.23789. PMID 20658466.

[13] Zeitlmann, L; Sirim P; Kremmer E; Kolanus W. "Cloning of ACP33 as a novel intracellular ligand of CD4". J. Biol. Chem. (United States), 2001: 276 (12): 9123-32. doi:10.1074/jbc. M009270200. ISSN 0021-9258. PMID 11113139. 
[14] Rudd CE, Trevillyan JM, Dasgupta JD, Wong LL, Schlossman SF. "Pillars article: the CD4 receptor is complexed in detergent lysates to a protein-tyrosine kinase (pp58) from human T lymphocytes. 1988". J. Immunol. 2010; 185 (5): 2645-9. PMID 20724730.

[15] Greenwood BM, Armstrong JRM. Comparison of two simple methods for determining malaria parasite density. Transactions of the Royal Society of Tropical Medicine and Hygiene. 1991; 85: 186-188.

[16] Cheesbrough, Monica. District Laboratory practice in tropical Countries part1. 2002: Cambridge low-price edition. Cambridge University Press.

[17] Ignatius C M, Emeka EN, Blessing NE .Effect of Malaria
Parasitaemia on Liver Enzyme Tests. International Journal of Tropical Medicine.2008: 3: 49-52.

[18] Oduola. T, Bello .I and Avwioro .G. Hepatotoxicity and nephrotoxicity evaluation in Wistar albino rats exposed to Morinda lucida leaf extract. N Am J Med Sci. 2010; 2(5): 230-233.

[19] Uzuegbu U.E. and Emeka C.B. Changes in Liver Function Biomarkers among Malaria Infected Patients in Ikeja Lagos State, Nigeria. Current Research Journal of Biological Sciences. 2010:3(3): 172-174, 2011 ISSN: 2041-0778.

[20] Bhalla A, Suri V, Singh V. "Malarial hepatopathy". Journal of Postgraduate Medicine. 2006:52 (4): 315-20. PMID 17102560. 